DOI: https://doi.org/10.12957/teias.2020.48626

\title{
TECNOLOGIAS DIGITAIS, LITERATURA INFANTIL E MULTILETRAMENTOS NA FORMAÇÃO DE PROFESSORAS
}

Terezinha Fernandes

Resumo

O estudo objetiva compreender a relação entre literatura infantil e tecnologias digitais na obra literária $A$ vida de Ada Lovelace discutindo insurgências, tensões e multiletramentos na formação de professoras que atuam com crianças. A pesquisa foi desenvolvida com inspiração na metodologia da pesquisa-formação, na disciplina de Múltiplas Linguagens: Literatura Infantil, em um curso de licenciatura de uma universidade pública federal, com duas professoras formadoras e doze orientadoras acadêmicas. Os resultados apontam as potencialidades da obra em análise tanto na formação de professoras, quanto no trabalho educativo com crianças por ser disparadora de reflexões sobre os entrelaçamentos entre Literatura infantil e tecnologias digitais e mobilizadora de diversos letramentos.

Palavras-chave: tecnologias digitais; formação de professoras; multiletramentos.

\section{DIGITAL 'TECHNOLOGIES, CHILDREN'S LITERATURE AND MULTILITERACIES IN TEACHER'S FORMATION}

Abstract

The study aims to understand the relationship between children's literature and digital technologies in the literary work $A$ vida de Ada Lovelace discussing insurgencies, tensions and multiliteracies in the formation of teachers who work with children. The research was developed with inspiration in the research-training methodology, in the Multiple Languages: Children's Literature discipline, in a degree course of a federal public university, with two teacher trainers and twelve academic advisors. The results point out the potential of the work under analysis both in teacher's formation and in the educational work with children as it triggers reflections intertwining children's literature and digital technologies as mobilizes several literacies.

Keywords: digital technologies; teacher's formation; multiliteracies.

\section{TECNOLOGIAS DIGITALES, LIT'ERATURA INFANTIL Y MULTIALFABETIZACIONES EN FORMACIÓN DEL PROFESORADO}

Resumen

El estudio tiene como objetivo comprender la relación entre la literatura infantil y las tecnologías digitales en el libro literario $A$ vida de Ada Lovelace, qué trata con insurgencias, tensiones y multialfabetizaciones en la formación del profesorado qué trabajan con niños. La investigación se desarrolló con la inspiración de la metodología de investigación y formación, en la disciplina de Múltiples Idiomas: Literatura Infantil, en un curso de grado de una universidad pública federal, con dos formadores de maestros y doce asesores académicos. Los resultados señalan el potencial del libro bajo análisis, tanto en la formación del profesorado como en el trabajo educativo con niños, ya que desencadena reflexiones sobre el entrelazamiento entre la literatura infantil y las tecnologías digitales y moviliza diversas alfabetizaciones.

Palabras clave: tecnologías digitales; formación del profesorado; multialfabetizaciones. 
DOI: https://doi.org/10.12957/teias.2020.48626

\section{CONSIDERAÇÕES INICIAIS}

Vivemos atualmente a chamada cultura digital, em que outros modos de receber, consumir, criar e produzir mensagens e produtos mudaram com o uso do computador, da internet e da sua multiplicidade de linguagens digitais. Essas mudanças também provocam outros modos de ação dos sujeitos com os diferentes artefatos, aplicativos e interfaces usados na comunicação. E, nesse contexto cultural de mudanças, as relações sociais mediadas pelas tecnologias digitais em práticas sociais e educativas provocam tensões e insurgências, as quais estamos em busca de compreender, em especial quando colocamos a ênfase desses processos em diálogo com a literatura infantil na formação de professoras.

Em busca dessas compreensões, a presente pesquisa foi desenvolvida com inspiração na metodologia da pesquisa-formação (SANTOS, 2014) por se tratar de um trabalho em que as professoras formadoras e orientadoras acadêmicas ${ }^{1}$ envolvidas formam e se formam ao mesmo tempo. O estudo teve como dispositivo de produção de dados uma formação mensal presencial de uma disciplina e encontros a distância, mediados por duas professoras formadoras, com doze professoras da rede pública municipal que atuam em quatro polos do estado de Mato Grosso como orientadoras acadêmicas no curso de licenciatura em Pedagogia, modalidade a distância (EaD).

O recorte para este estudo é a obra A vida de Ada Lovelace, de Silvia Amélia Bim (2018)2, como arte inspiradora em seu potencial de provocar o debate em torno da literatura destinada à criança e a relação desta com as tecnologias digitais. A questão que orienta as discussões e reflexões é: a obra literária $A$ vida de Ada Lovelace possibilita a mobilização de multiletramentos na relação literatura e tecnologias digitais na formação de professoras que atuam com crianças? Nessa direção o objetivo é compreender a relação entre literatura infantil e tecnologias digitais na obra literária $A$ vida de Ada Lovelace discutindo insurgências, tensões e multiletramentos na formação de professoras que atuam com crianças.

As temáticas que compõem este artigo estão dispostas em quatro tópicos, sendo: aspectos metodológicos; literatura infantil e tecnologias digitais; ciência e tecnologia na obra $A$ vida de Ada Lovelace; e literatura, tecnologias digitais e multiletramentos na formação de professoras.

Por último, nas considerações finais, apresentam-se os desafios, as possibilidades e as perspectivas do tema em estudo.

\section{ASPECTOS METODOLÓGICOS}

O trabalho desenvolvido buscou apoio na metodologia da pesquisa-formação na cibercultura (SANTOS, 2014), em diálogo com a multirreferencialidade (ARDOINO, 1998), para lançar um olhar mais complexo e heterogêneo aos processos de formação de professoras e a sua compreensão enquanto fenômeno educativo plural e suas nuances na contemporaneidade.

\footnotetext{
${ }^{1}$ No Projeto Pedagógico do Curso de Licenciatura em Pedagogia do NEAD/UFMT é usado o binômio orientador(a) acadêmico(a) para designar o(a) professor(a) que atua na mediação entre o(a) professor(a) formador(a), o material didático impresso e digital e demais sujeitos no processo e percurso de ensino e aprendizagem e avaliação dos(as) estudantes. No âmbito da Universidade Aberta do Brasil (UAB), esse(a) profissional é designado(a) como tutor(a).

2 A divulgação da obra tem apoio da Sociedade Brasileira de Computação (SBC) e faz parte das ações do Programa Meninas Digitais para incentivar a maior representatividade de mulheres na computação. Fez parte do trabalho de conclusão de curso de especialização em Narrativas Visuais na Universidade Tecnológica Federal do Paraná, realizado por Kiara Cabral, com a orientação de Eunice Liu, com o título: Design editorial infantil: uma narrativa ilustrada sobre Ada Lovelace.
} 
DOI: https://doi.org/10.12957/teias.2020.48626

O estudo foi desenvolvido a partir de uma formação mensal presencial e orientações a distância mediadas por tecnologias digitais (TD) em rede, na disciplina de Múltiplas Linguagens: Literatura Infantil no curso de licenciatura em Pedagogia, modalidade a distância, da Universidade Federal de Mato Grosso. Os encontros foram conduzidos por duas professoras formadoras (sendo uma delas a autora deste texto) com doze professoras que atuam no curso na função de orientadoras acadêmicas, junto com as(os) estudantes, em quatro polos do estado de Mato Grosso.

A motivação para o estudo, no contexto da formação citada, surgiu a partir da leitura compartilhada da obra $A$ menina da cabeça quadrada, de Emília Nunes (2017), realizada por uma das orientadoras participantes. Esta obra literária conta a história de uma menina que usa dispositivos tecnológicos digitais, como celular, tablet e computador, para ler, jogar e brincar. Outras crianças, enquanto isso, brincam nas ruas e nos parques com brinquedos analógicos e tradicionais e, por isso, continuam com suas cabeças redondas. Já a menina que usa os artefatos tecnológicos digitais para as mesmas ações e brincadeiras fica com a cabeça quadrada.

A leitura da obra foi disparadora de tensões e debates acerca das tecnologias digitais na infância e na formação de professoras. Soaram-se vozes como "sou a favor de crianças não usarem celular, tablet, é preciso ter cautela e controle sobre o uso excessivo de tecnologias digitais pelas crianças; não levaria uma obra como essa para ler com as crianças em sala de aula; levaria a obra para abrir um debate na formação de professoras". Enfim, a leitura provocou estranhamento, discordâncias e tensões e apontou a necessidade de problematização, para além daquela formação.

Provocada pelos tensionamentos e debates, uma das professoras formadoras sugeriu como contraponto a leitura da obra literária $A$ vida de $A d a$ Lovelace ${ }^{3}$. A história conta que "[...] há muitos e muitos anos nasceu Ada Lovelace, uma menina inteligente e criativa que uniu matemática e imaginação para projetar o funcionamento de uma máquina muito interessante” (BIM, 2018, p. 1). Quando criança, criou o projeto de um cavalo voador e, quando adulta, criou o protótipo do primeiro computador de que se tem notícia no mundo. $\mathrm{O}$ seu projeto não saiu do papel, e o primeiro computador só foi criado cem anos após a sua morte. Em 1982 foi criada uma linguagem de computador em seu nome e desde 2009, na segunda terça-feira do mês de outubro, é realizado o Ada Lovelace Day em sua homenagem.

A partir da leitura desta obra e da problematização das tecnologias digitais na infância, a professora formadora sugeriu às orientadoras participantes que levantassem obras literárias com a temática das tecnologias. Em continuidade à formação, foram levantadas dez obras, as quais foram lidas, resenhadas e debatidas em um encontro presencial e orientações a distância com apoio teórico às resenhas em Debus; Cintra; Spengler (2013).

A realização das leituras e a elaboração das resenhas favoreceram o desenvolvimento dos letramentos científicos das orientadoras, uma vez que mobilizaram conhecimentos relacionados à produção escrita deste gênero textual, bem como a comunicação e socialização das mesmas ao grande grupo. As obras resenhadas farão parte de estudos posteriores e produções escritas pelo grupo de orientadoras acadêmicas participantes.

O recorte para o presente estudo é a obra $A$ vida de Ada Lovelace como arte inspiradora em seu potencial de provocar o debate em torno da literatura destinada à criança e a relação desta com as tecnologias digitais. A questão que orienta as discussões e reflexões é: a obra literária $A$ vida de Ada Lovelace possibilita a mobilização de multiletramentos na relação literatura e tecnologias digitais

\footnotetext{
${ }^{3} \mathrm{O}$ enredo do conto $A$ vida de Ada Lovelace permite a intertextualidade com outros contos, como $A$ moça tecelã; Sebastiana e Severina; A filha do moleiro; Penélope, da Odisséia de Homero; Ariadne, do mito do Minotauro; As três parcas e Rumpelstiltski; A Gata Borralheira; entre outros.
} 
na formação de professoras que atuam com crianças? Nessa direção o objetivo é compreender a relação entre literatura infantil e tecnologias digitais na obra literária $A$ vida de Ada Lovelace discutindo insurgências, tensões e multiletramentos na formação de professoras que atuam com crianças.

Nesse sentido, na pesquisa-formação (SANTOS, 2014), os processos de formação são pautados em práticas coletivas e dialógicas em que contexto, pesquisadoras, participantes e experiências nos percursos formativos não são dissociados, ao contrário, são favorecedores do olhar multirreferencial e da sua interpretação e compreensão como fenômenos da cultura contemporânea, plural e complexa. E, nessa relação, os conhecimentos construídos possibilitam mudanças nas práticas formativas e nos sujeitos participantes dos atos formativos.

\section{LITERATURA INFANTIL E TECNOLOGIAS DIGITAIS}

Há muito tempo se discute sobre infância e o uso de tecnologias pelas crianças, o que gera debates sobre as mudanças de comportamento e os modos de se relacionar com a cultura lúdica, com as maneiras de brincar, de interagir entre pares, entre outros. Isso nos aponta para práticas culturais infantis em processo de transformação, as quais necessitam ser problematizadas, compreendidas e apropriadas por professoras que atuam com crianças para apoiar mediações condizentes com a cultural atual.

Ao analisar perspectivas acerca das mídias na infância, Buckingham (2007) destaca duas correntes: a primeira culpabiliza as mídias pela "morte da infância", e a segunda é daqueles que as veem como vias para "liberação das crianças". Para o autor, "nas duas perspectivas, as mídias têm um papel central, não apenas refletindo as mudanças sociais e culturais mais amplas, mas também as produzindo" (BUCKINGHAM, 2007, p. 275). O autor destaca que ambas as perspectivas são exageradas e essencialistas, tanto do ponto de vista da infância quanto dos meios de comunicação, pois o padrão de mudanças é complexo e ambíguo e, para tanto, é necessário ir além de perspectivas excludentes, "ou isto ou aquilo", e sim situar o debate na relação com seus contextos sociais.

No contexto desta cultura em movimento, crianças acompanham as mudanças por ela instauradas, as quais se refletem em seu modo de atuar no mundo com os diferentes grupos sociais com que convivem durante a infância. Independentemente da tecnologia em uso, a criança é ativa, imaginativa, criativa e criadora. Assim era com Ada Lovelace.

Aos doze anos, o seu grande projeto era construir um cavalo mecânico voador. Fez vários estudos para compreender como os pássaros voavam. Fez também vários desenhos projetando o cavalo. Embora Ada não tenha conseguido voar em seu cavalo mecânico, deixou todos os estudos e desenhos registrados em um livro chamado Voologia (BIM, 2018, p. 9).

Ada possuía excepcional conhecimento matemático e, à sua época, a tecnologia para registrar esse conhecimento era o caderno ou diário físicos nos quais escrevia e desenhava. Aliadas a este conhecimento específico de Ada, estavam presentes a imaginação fértil e a sensibilidade artística e estética, que também são marcas da arte e da literatura.

Estes são, segundo Paulino (2010), entrelaçamentos possíveis, pois, entre os diversos letramentos, o letramento literário é um processo ativo de apropriação da literatura enquanto construção de sentidos e suas estratégias, a construção de um repertório textual e linguístico e a imersão do leitor no campo simbólico. Os multiletramentos, para Street (2014), são heterogêneos e abarcam as dimensões sociais, políticas e culturais das práticas sociais. $\mathrm{O}$ autor destaca que estes 
DOI: https://doi.org/10.12957/teias.2020.48626

múltiplos letramentos variam conforme o tempo e o espaço e são contestados nas relações de poder nas práticas em sociedade.

Para Petit (2009, p. 115), “[...] não importa o meio onde vivemos e a cultura que nos viu nascer, precisamos de mediações, de representações, de figurações simbólicas para sair do caos, seja ele exterior ou interior [...] para que possamos nos instalar em nós mesmos". Nesse sentido, é fundamental a formação leitora da criança na cultura digital e a mobilização de multiletramentos, considerando serem estes uma apropriação pessoal em práticas sociais literárias. É possível uma formação de professoras que atuam com crianças por meio de experiências estéticas, que humanizam as relações e atuam no campo do simbólico, fazendo uso de artefatos digitais.

As práticas sociais com a literatura, conforme Paulino (2010), envolvem a apropriação de um repertório de conhecimentos que abarcam o textual (histórias, poemas etc.), os conhecimentos linguístico-formais, os elementos de construção de narrativas, os elementos de construção de sentido, os elementos de leitura de mundo até a imersão no campo simbólico (fantasia, imaginação, criatividade, prazer etc.) e, com isso, o reconhecimento do valor cultural, social, estético e educativo para a sensibilidade e humanização das relações na escola e na vida das pessoas. Daí a relevância da sua presença na formação de professoras que trabalham com crianças.

A literatura e seus ideais e valores nem sempre foram atrelados ao conceito de criança e infância como conhecemos contemporaneamente. Esta preocupação é percebida na produção literária a partir do reconhecimento de que a criança é um ser em crescimento e desenvolvimento e que a infância é uma etapa importante da sua vida. Com isso, segundo Coelho (2000), a literatura passa a ser compreendida como o conjunto de publicações com características mais próximas desta fase da vida da criança. $\mathrm{Na}$ contemporaneidade, para Coelho (2000), a produção literária se caracteriza pela heterogenia e diversidade de linhas e tendências de criação e produção e de gêneros e temáticas, o que favorece a diversificação das práticas.

A literatura, para Coelho (2000), é linguagem e arte e, como toda linguagem e toda arte, expressa experiências humanas; por isso, dificilmente é definida com exatidão. Ela expressa finalidade e função estético-formativa, que envolve a sensibilidade, a beleza da palavra e das imagens e favorece o desenvolvimento da fantasia e do imaginário da criança. Ela é fenômeno da criatividade que representa o mundo, o homem e a vida por meio de palavras. Funde os sonhos e a vida prática, o imaginário e o real, os ideais e sua possível ou impossível realização.

As discussões sobre literatura e inovações tecnológicas faziam parte das preocupações de Antonio Candido (2004) desde a década de 1970, quando evidenciava a função social da literatura em contato com os modos de comunicação que emergiam naquele contexto. O autor destacava a criação de alternativas para a necessidade humana da fantasia e do conhecimento simbólico da realidade. Para o autor, independentemente do nível de desenvolvimento tecnológico, a humanidade precisa da ficção e da fantasia, e a literatura funciona como resposta a essa necessidade universal, reconhecendo a ficção em constante interação com a realidade prática e seu papel na formação humana.

A compreensão da literatura como força humanizadora de Antonio Candido (2004) contribui para pensarmos a formação da personalidade da criança e constitui-se em uma forma de conhecimento de si e do mundo. Junto a esta compreensão, é salutar e possível, o desenvolvimento de espaços de leitura literária para crianças com vistas a potencializar a formação de comunidades de leitores e promover a ampliação dos letramentos literários, e consequentemente, das maneiras de ver e viver no mundo.

No cenário da cultura digital, conforme Santaella (2012, p. 230), “[...] o conceito de literatura se expande em função da profusão de formatos, protótipos e estilos no ciberespaço". A autora 
destaca que surgem diversas denominações como "[...] literatura gerada por computador, literatura informática, infoliteratura, literatura algorítmica, literatura potencial, ciberliteratura, literatura generativa, hiperficções, texto virtual, geração automática de texto, poesia animada por computador, poesia multimídia" (SANTAELLA, 2012, p. 230), e com isso, as interações dos leitores com os fanfics, blogs, e-books, ciberficção, videopoemas e outras narrativas hipermidiáticas também são transformadas.

Para Xavier (2004), as capacidades de ficcionalizar, construir mundos que dialogam com a realidade prática, transgredir convenções e mediar relações sociais e culturais são potencialidades da literatura. E esta, assim como outras linguagens, sofre as influências das trocas comunicativas no ciberespaço, bem como os leitores assumem papéis cada vez mais dinâmicos, atuando com as interconexões entre links, hiperlinks e hipertextos como uma "[...] forma híbrida, dinâmica e flexível de linguagem que dialoga com outras interfaces semióticas, adiciona e acondiciona à sua superfície formas outras de textualidade" (XAVIER, 2004, p. 171).

Nesta direção, as dez obras que foram levantadas, lidas e resenhadas pelas orientadoras acadêmicas e pelas professoras formadoras apontaram que, na atualidade a produção literária para crianças busca uma aproximação com a cultura digital e seus artefatos tecnológicos, trazendo subjacente a isso uma concepção de criança, infância e tecnologias digitais, discutindo usos e consumos, em diálogo com insurgências como a tecnofobia e outras temáticas sociais que geram tensões a serem problematizadas e compreendidas em processos formativos. $\mathrm{Na}$ obra $A$ vida de Ada Lovelace, a relação de gênero foi disparadora de discussões sobre a mulher e o seu papel na ciência e tecnologia, além de mobilizadora de multiletramentos.

\section{CIÊNCIA E TECNOLOGIA NA OBRA $A$ VIDA DE ADA LOVELACE}

A possibilidade de refletir a realidade em que se vive e o universo social em que se está inserido nem sempre é algo desejável, pois pode despertar uma nova visão de mundo, valores, sensibilidade e criatividade. Como arte e, aparentemente, distante do mundo real, a literatura desperta significados e sentidos, levando o leitor a experiências estéticas para interpretar a própria condição humana e ao enfrentamento de questões sociais, políticas e ideológicas do seu tempo. Ada Lovelace vivia este conflito.

Sua mãe era uma hábil matemática [...]. Seu pai um influente poeta romântico [...]. Sua rotina diária era de muito estudo: Matemática, Física, Química, Biologia, Engenharia, Música, Francês... mas nada, absolutamente nada de poesia. Poesia poderia despertar a imaginação e isso, segundo a mãe de Ada, talvez pudesse ser perigoso para a personalidade da filha (BIM, 2018, p. 7).

É importante destacar que, na primeira metade do século XIX, Ada vivia em um contexto em que mulheres não tinham direito e acesso à formação universitária como temos atualmente. Ela tinha um mentor, professor da Universidade de Londres, que a ensinava matemática e lógica em casa, influenciada pelo interesse da mãe pelas áreas. Além disso, somente após 26 anos da morte de Ada é que a primeira universidade inglesa permitiu que mulheres se graduassem.

Para ser uma matemática engajada em projetos inovadores, levando-a ao reconhecimento do seu papel na ciência e tecnologia, era necessário, na visão de sua mãe, agir com a razão para não se distrair dos estudos. Por isso, nada de poesia, imaginação e criatividade "[...] para evitar que a filha tivesse um comportamento e uma personalidade parecidos com os do pai” (BIM, 2018, p. 6). 
Mas "Ada viveu todos os dias da sua vida sendo uma mistura de seus pais, combinando com muita criatividade razão e emoção" (BIM, 2018, p. 12).

Isso fica evidente, segundo Isaacson (2014), nas cartas que Ada trocava com sua mãe e em um ensaio, escrito por ela em 1841, em que destacava a matemática e a imaginação como faculdades de fazer combinações entre coisas, fatos e ideias originais, infinitas e em mutação, aplicáveis à ciência e tecnologia, as quais levaram-na a um "[...] imenso desenvolvimento da imaginação, de modo que não tenho dúvida de que, caso continue meus estudos, deverei no momento certo me tornar Poeta" (ISAACSON, 2014, p. 30).

Para Paulino (2010), a literatura deve ser vivida pela criança na escola e na vida em toda a sua integridade para que seja possível assegurar-lhe o poder das significações. Para a autora, a criança não corre perigo com a literatura, seja qual for a temática que ela abarque, sendo necessário à escola e aos adultos ultrapassarem os dogmas disciplinares que cerceiam a arte literária, colocando a ênfase nas mediações a serem feitas.

Assim como a literatura ocupou um não lugar (AUGÉ, 1994) na vida de Ada Lovelace, a ciência e a tecnologia foram historicamente ausentes da vida da mulher. A poesia por ser considerada uma marca identitária marginal; e a ciência e tecnologia pela impossibilidade de ocupar um lugar social que não lhe pertence e por representar a afirmação de si mesma a ela negada.

Junto com seu amigo Charles Babagge, ela projetou a construção de uma máquina gigante para fazer cálculos complexos, usando todo o seu conhecimento matemático, mas "Ada queria ir além: E se a máquina pudesse tocar música e mostrar tanto letras quanto números? Ela estava descrevendo um computador, muito antes de os computadores modernos serem inventados! Ada escreveu o primeiro algoritmo para computador da história" (FAVILLI; CAVALLO, 2017).

Para Antonio Candido (2004), as manifestações artísticas, entre elas a literatura, educam o sentimento e organizam as formas caóticas presentes no interior humano, pois atuam, em grande parte, no inconsciente e no subconsciente, na busca de equilíbrio. Para o autor, a literatura é fator indispensável de humanização, uma necessidade universal, cuja satisfação constitui um direito inalienável, pois, "[...] assim como não é possível haver equilíbrio psíquico sem o sonho durante o sono, talvez não haja equilíbrio social sem a literatura" (CANDIDO, 2004, p. 176).

Ada representa as mulheres que, ao longo da história, lutaram para ocupar seu espaço social e que, por suas trajetórias de vida em lugares, tempos e contextos de deslocamentos, recessões econômicas, situações de guerra e violência, enfrentaram crises, mudanças e transformações em suas vidas. Ada estava "[...] vivendo os últimos anos da Revolução Industrial e, assim como outros cientistas, o grande interesse deles era construir máquinas para executar diversas atividades que antes eram feitas apenas pelas pessoas" (BIM, 2018, p. 18). E a mãe de Ada era aficionada pelos avanços tecnológicos da Revolução Industrial, portanto, incentivadora dos seus estudos e suas criações nesta área.

Por um lado, a mãe de Ada negava a literatura. Quanto a isso “[...] não há e nunca houve uma verdadeira arte que valesse o mesmo para todos no mundo [...] as pessoas têm expectativas, preferências e repertórios diferentes. [...] há as diferenças de critérios de valor que dependem fundamentalmente de cada época histórica" (PAULINO, 2010, p. 129). Por outro lado, ela a incentivava a estudar áreas do conhecimento historicamente ocupadas por homens. Talvez por ter sido um sonho não realizado, projetou-o em sua filha. E Ada vislumbrou uma máquina que unia os dois atributos: “[...] a máquina tinha potencial para processar não só números como quaisquer notações simbólicas, incluindo notações musicais e artísticas. Ada viu a poesia dessa ideia e passou a incentivar os outros a ver a mesma coisa" (ISAACSON, 2014, p. 36). 
A sua criação representa hoje as conquistas das mulheres em ciência, tecnologia, engenharia e matemática e, com as perguntas que fazia em suas notas sobre o uso prático da máquina de calcular, buscava responder como as pessoas se relacionavam com tecnologias em atividades cotidianas, indissociadas de suas potencialidades poéticas. Assim, "Ada é (re)conhecida por ser a primeira pessoa que escreveu um algoritmo, um programa de computador, antes mesmo dos computadores existirem. [...] era considerada uma máquina calculadora humana” (BIM, 2018, p. 15).

As ideias de Ada possibilitaram-na pensar o protótipo de uma máquina, ideia esta que, segundo Isaacson (2014), contribuiu com a Revolução Industrial. Assim como o motor a vapor, o tear mecânico e o telégrafo foram importantes para os avanços desta Revolução, posteriormente foram igualmente importantes o computador, o microchip e a internet para a Revolução Digital. "No coração de ambas as revoluções estavam inovadores que combinavam imaginação e paixão com tecnologia assombrosa, uma mistura que produziu a ciência poética de Ada" (ISAACSON, 2014, p. 23).

Conforme Isaacson (2014), Ada recebeu a honra de ser chamada de "a primeira programadora de computador do mundo" e os quatro conceitos deixados por ela em suas notas são fundamentais para a área de ciência e tecnologia, os quais sintetizamos para elucidar suas contribuições:

- distinção entre a Máquina Diferencial e a Máquina Analítica;

- descrição de uma máquina de propósito geral (não limitada à matemática e aos números, uma "ciência poética", a partir da qual seria possível compor uma peça musical elaborada e científica);

- descrição em detalhes, passo a passo, do funcionamento de um programa de computador ou algoritmo;

- levantamento do tópico metafísico mais fascinante envolvendo computadores e inteligência artificial: "as máquinas podem pensar?”.

As reflexões sobre o lugar da literatura na vida dos sujeitos e da ciência e tecnologia na vida das mulheres, assim como outras temáticas sociais subjacentes em obras literárias infantis como a de Ada Lovelace, mostram que elas podem contribuir como dispositivos mediadores de debates na formação de professoras na cultura digital e mobilizar multiletramentos sem perder o estatuto de arte literária.

\section{LITERATURA, TECNOLOGIAS DIGITAIS E MULTILETRAMENTOS NA FORMAÇÃO DE PROFESSORAS}

Realizar formações de professoras abertas às diferentes relações com as transformações e avanços tecnológicos que revolucionaram o mundo e a vida das pessoas, aliadas à literatura como arte de expressar e significar o mundo, é um enorme desafio. Em um mundo mediado por tecnologias digitais, espaços como bibliotecas e museus virtuais e artefatos digitais como e-books, revistas online, vídeos, sites e outros suportes do texto literário, são fundamentais à participação ativa em experiências literárias para uma educação estética e da sensibilidade, deslocando a ênfase às mediações das professoras e outros adultos na promoção da leitura, produções, criações e sentidos qualitativos pela criança.

Como professoras podem atuar para levar a criança a fazer suas escolhas de leituras literárias na cultura digital? Como despertar o gosto em apreciar construções e significações estéticas outras? 
O que a criança produz na cultura digital com o uso de artefatos tecnológicos aliados a literatura? Como as crianças habitam espaços digitais e virtuais e o que produzem com a arte literária? Que tensões e insurgências emergem na relação literatura infantil e tecnologias digitais na atualidade? São questões a serem problematizadas na formação de professoras.

Para Jenkins (2009), a participação plena de jovens e crianças na cultura da convergência é fundamental. $\mathrm{O}$ autor destaca as capacidades que estes possuem em unir o seu conhecimento ao conhecimento coletivo ou à inteligência coletiva, por meio de dramas éticos, ficções populares e outros. Destaca ainda a chamada cultura participativa para desenvolver suas narrativas, interpretação de papéis, análises literárias, edições, editorações e outras criações que fazem na internet, tendo a literatura como fonte de inspiração. Por meio da participação nestes espaços desenvolvem letramentos de modo mais recreativo e sem controle direto do adulto, em oposição às práticas comumente exercidas na escola.

Há muito tempo, Buckingham (2007) apontava que “[...] em relação às mídias temos de reconhecer as habilidades que as crianças têm em avaliar as representações daquele mundo disponíveis para elas e identificar o que elas ainda precisam aprender para fazê-lo de forma mais produtiva" (BUCKINGHAM, 2007, p. 278). Para o autor, na relação entre infância e mídias, existem continuidades e transformações relevantes, e estas afetam, de forma distinta, grupos diferentes de crianças. Não há como negar que, de um lado, há o controle do adulto e institucional, a infância sendo mais comercializada, as crianças se tornando mais consumidoras de artefatos midiáticos, lazer etc., e de outro lado, as desigualdades de capital material sendo mais acentuadas e a vida cultural das crianças se transformando por meio dos ambientes midiáticos em que vivem. Para Buckingham (2007), a postura do adulto não deve ser defensiva ou protecionista, mas sim mediadora e, sobretudo, baseada na clareza de que políticas públicas culturais e educacionais e os princípios que orientam e informam tais políticas, engendram-se nos contextos culturais dos sujeitos.

Com a mediação do seu mentor, Ada elaborou o primeiro algoritmo e abriu portas para outras mulheres e homens cientistas aprimorarem seus conceitos e desenvolverem novas tecnologias. Ada "[...] sabia muito sobre matemática e temperava todo esse conhecimento com a mais saborosa imaginação" (BIM, 2018, p. 24). Uma personalidade analítica, ligada à arte, que vivia uma simbiose entre conhecimentos lógicos, matemáticos e artísticos, contribuiu para suas ideias e criações. "A história de Ada prova que a imprescindível combinação entre uma forte imaginação e uma incrível habilidade matemática pode gerar ideias inovadoras para melhorar a vida das pessoas" (BIM, 2018, p. 26).

É necessário colocar em debate a binaridade entre bom e mau na relação entre literatura infantil e tecnologias e as inúmeras possibilidades de explorar as temáticas na formação de professoras e na educação de crianças. Há muitas tensões a serem problematizadas e compreendidas sobre elas no contex to da cultura digital, dialogando com valores estéticos e éticos. Com as transformações tecnológicas, sociais e culturais surgem novos artefatos, linguagens, modos de uso, consumo, produção e compartilhamento de informações e conhecimentos, e com isso, os modos de mediação do adulto entre os artefatos tecnológicos e as crianças em práticas sociais e educacionais também mudam significativamente.

Neste contexto, em que o espaço de comunicação e sociabilidade é desterritorializado, existem implicações culturais como a copresença, a interação, a leitura, a criação de narrativas e a inteligência coletiva. Esses espaços virtuais com plataformas, mídias e redes sociais promovem outros tipos de vivências, tanto do ponto de vista do uso do artefato que suporta a mensagem literária, quanto da própria experiência de leitura e criação literária, que saem do lugar físico das 
DOI: https://doi.org/10.12957/teias.2020.48626

bibliotecas para os espaços fluidos da internet e dos dispositivos móveis, possibilitando novas apropriações e vivências.

São essas mudanças que a formação de professoras pode contemplar, com modos de atuação que promovam estímulo à leitura, valorização do patrimônio cultural e artístico e práticas literárias com artefatos e linguagens digitais que mobilizem multiletramentos. Jenkins (2009) afirma ser este um desafio da época em que vivemos, sendo necessário aprender com a cultura da convergência, inteligência coletiva e cultura participativa. Para o autor, é fundamental compreender como as práticas das crianças e dos jovens com literatura e suas autorias ocorrem e como elas influenciam as noções conflitantes dos letramentos que emergem e moldam a cultura digital.

Trata-se de transformações culturais e redimensionamentos das relações entre os sujeitos e os conhecimentos com a hipertextualidade, interatividade e relações interpessoais no ciberespaço. Lévy (1999) há tempos nos ensina que as tecnologias que o ciberespaço suporta ampliam, exteriorizam e alteram funções cognitivas humanas, a memória (bancos de dados, fichários digitais, hipertextos), a imaginação (simulações), a percepção (sensores digitais, telepresença, realidades virtuais), o raciocínio (inteligência artificial, modelização de fenômeno complexos). E, neste contexto, a literatura é transmidiada, pois o conteúdo de uma narrativa que tínhamos, até pouco tempo, somente em um livro físico, atualmente está, ao mesmo tempo, em diversos formatos e plataformas digitais, transitando de uma mídia a outra, como do e-book ao filme, do filme ao jogo online, do jogo online ao vídeo, do vídeo à série de TV, dentre outros, para o acesso pelas pessoas, a qualquer hora e lugar.

Para Maddalena; D’Ávila; Santos (2018), nestes espaços as pessoas contam histórias por meio de fotografias e vídeos, criam Visual Storytellings efêmeras, usando as redes sociais, como Facebook, Instagram e WhatsApp. Para as autoras, essas plataformas são potentes espaços de narrativas, histórias cotidianas, crônicas e diário de viagens. Por meio delas, as pessoas mixam narrativas autorais usando a linguagem escrita, fotografias, vídeos, mapa de localização e hashtags. $\mathrm{Na}$ opção Stories criam narrativas efêmeras, com pouco tempo de duração, autodestrutivas. Mas há opções, nas mesmas redes sociais, para conservar no tempo as narrativas e imagens e, nesse sentido, funcionam como repositórios de histórias pessoais e coletivas. São novos modos de autoria, coautoria, colaboração e compartilhamento de histórias misturando diversas linguagens.

São muitas as contribuições que podemos vislumbrar com os espaços virtuais e artefatos tecnológicos digitais contemporâneos aliados ao trabalho educativo com a literatura, e que, ao levarmos como proposta para compor a formação de professoras e também com as crianças na escola, abrimos um leque de possiblidades. Por exemplo, após a leitura da obra $A$ vida de $A d a$ Lovelace, na formação de professoras, no livro em formato físico, fomos à internet em busca do livro em formato digital, não o encontramos, mas localizamos sites com a sua biografia, textos relacionados a ela em e-bock sobre a história da computação, trabalhos acadêmicos como artigos e dissertação de mestrado sobre a sua contribuição à informática e gênero na computação, muitas imagens relacionadas a ela a sua criação e vídeos com a sua biografia, dentre outros. Estes são dispositivos que poderão complementar outras formações de professoras e o trabalho com as crianças na escola.

Quanto aos multiletramentos na relação literatura, ciência e tecnologia, a obra $A$ vida de Ada Lovelace, além de contemplar a ludicidade, a criatividade, a imaginação, a sensibilidade e a beleza, que são próprias da arte literária, mobiliza importantes dimensões dos letramentos digitais que podem ser contempladas em formações educativas com professoras e crianças: 
DOI: https://doi.org/10.12957/teias.2020.48626

- computacional - conhecer as notas matemáticas que constituíram a primeira descrição de um computador e de um software; a capacidade dos computadores para além do mero cálculo ou processamento de números; o desenho do primeiro protótipo de computador, uma máquina com características de computadores eletrônicos, digitais e reprogramáveis que só seriam possíveis um século depois;

- inteligência artificial - reconhecer que a frase até hoje relacionada à inteligência artificial é ligação a dúvida de Ada: "máquinas feitas por homens podem realmente pensar?";

- inteligência coletiva ou colaborativa - saber que Ada mostrava, em suas notas, como as pessoas e a sociedade se relacionam com a tecnologia como um artefato de colaboração; trabalhava em parceria com seu amigo britânico, criador da máquina diferencial e do computador analítico;

- artístico - saber que a invenção de Ada inspirou Mary Shelley a escrever a história de Frankenstein - o homem-máquina, que depois deu origem à concepção do filme homônimo;

- literário - mostrar o valor da literatura na vida de Ada como experiência estética, humanizadora e mediadora de representações simbólicas entre suas invenções lógicas e matemáticas;

- gênero - compreender condicionantes históricos para que Ada fosse reconhecida como pioneira da computação somente após Alan Turing, criador da Máquina de Turing e pai da computação moderna, ter feito referência ao seu nome e trabalho; Ada também costumava frequentar festas, beber e jogar, hábitos incomuns para mulheres da sua época, portanto, é também considerada pioneira no movimento feminista.

As práticas sociais e educativas contemporâneas exigem das professoras e de outros adultos mediadores novas relações para atuar com a literatura e as tecnologias digitais com crianças, fazendo uso criativo, estético e ético dos artefatos e suportes que são veículos do texto literário. Nestas relações e interações as crianças constroem vivências, significações e sentidos qualitativos às práticas literárias e desenvolvem multiletramentos da cultura digital.

\section{CONSIDERAÇÕES FINAIS}

A cultura atual e sua dinâmica com o uso do digital em rede provoca mudanças nas relações dos sujeitos com o mundo e com os outros. São transformações que afetam as ações cotidianas, desde ler uma história, buscar uma informação, praticar lazer e entretenimento, comunicar-se com um amigo distante, compartilhar fotografia/vídeo em mídias e redes sociais, até as ações mais complexas, como a transformação de um conceito teórico em um artefato tecnológico digital. Estas ações são atualmente mediadas pelo digital em rede e promovem transformações culturais e redimensionamentos nas relações entre os sujeitos e o conhecimento. Esses redimensionamentos produzem novas necessidades de formação para que os sujeitos possam atuar imersos em contextos cada vez mais complexos.

E, nesses contextos, as ações dos sujeitos mediados pelas tecnologias digitais têm favorecido o desenvolvimento de diversos letramentos digitais. Com base nessas questões, este estudo partiu da dúvida sobre as potencialidades da obra literária $A$ vida de Ada Lovelace como mobilizadora de multiletramentos na formação de professoras que atuam com crianças, buscando compreender a relação entre literatura infantil e tecnologias digitais, discutindo tensões e insurgências entre e com as temáticas. 
O olhar à literatura infantil e às tecnologias digitais possibilita uma potente discussão entre as áreas, bem como às práticas culturais com a literatura em mudança, incidindo nos modos de interação, mediação, apropriação e construção de sentidos, e reconfigurando usos, consumo, produção e compartilhamento de mensagens literárias, portanto, entrelaçamentos disparadores de letramentos digitais em diversas dimensões.

O debate acerca da ciência e tecnologia na obra $A$ vida de Ada Lovelace provoca a tensão por serem um não lugar feminino, ou seja, um espaço não ocupado por mulheres. Há ainda o fato de a literatura para crianças trazer como temática a vida de uma mulher forte que, ao mesmo tempo em que é cientista com grandes ideias e criações tecnológicas, é sensível à arte literária e, com ela, também faz invenções. O debate possibilita vislumbrar que conhecimentos matemáticos, criação, inovação tecnológica, arte e beleza da palavra literária se combinam perfeitamente e trazem grandes potencialidades para os processos formativos de professoras.

As discussões em torno de literatura, tecnologias digitais e multiletramentos na formação de professoras, tendo em vista as mudanças tecnológicas, seus suportes, dispositivos e interfaces, possibilitam pensar na ampliação da participação, coparticipação, sociabilidades de crianças e jovens de modo mais ativo e colaborativo. Essas relações, na cultura digital, continuam sendo mediadas por professoras e outros adultos para que as experiências literárias e produções das crianças possam ser significativas e criadoras, potencializando multiletramentos.

Nessa discussão entram em pauta as políticas públicas e os princípios que orientam políticas culturais e educacionais nos contextos culturais em que os sujeitos vivem, pois é necessário levar em conta continuidades e transformações que afetam diferentes grupos sociais no que diz respeito a valores estéticos e éticos. As apropriações necessárias às professoras em formação caminham lado a lado com as necessidades que emergem da/na cultura digital, que traz consigo outras dimensões, como a cultura da convergência, inteligência, coletiva e colaborativa, comunicação ubíqua e seus desdobramentos nas práticas sociais e educativas.

Como todo estudo, destacamos o limite do tempo destinado a estas discussões em processos de formação de professoras, somente nas brechas possíveis, enquanto poderiam ocupar lugar de destaque. Situamos como possibilidade a continuidade dos estudos e a análise das temáticas subjacentes às obras que compõem a pesquisa-formação em andamento e as produções escritas.

Como perspectiva mais abrangente, há o desejo de ampliar as compreensões e os debates sobre o lugar que as tecnologias digitais ocupam no universo da literatura destinada às crianças na atualidade. Isso favorecerá, também, expandirmos os usos de artefatos tecnológicos digitais em ações educativas com a literatura infantil e desenvolver multiletramentos como práticas sociais que se engendram na cultura digital. 


\section{REFERÊNCIAS}

ARDOINO, Jacques. Abordagem multirreferencial (plural) das situações educativas e formativas. In: BARBOSA, Joaquim Gonçalves (org.). Multirreferencialidade nas ciências e na educação. São Carlos: EDUFScar, 1998.

AUGÉ, Marc. Não-lugares: introdução a uma antropologia da supermodernidade. Tradução Maria Lúcia Pereira. Campinas: Papirus, 1994.

BIM, Silvia Amélia. A vida de Ada Lovelace. Ilustração de Kiara Cabral. Porto Alegre: Editora SBC, 2018.

BUCKINGHAM, David. Crescer na era das mídias: após a morte da infância. Tradução Gilka Girardello e Isabel Orofino. São Paulo: Ed. Loyola, 2007.

CANDIDO, Antonio. O direito à literatura. In: Vários escritos. 4. ed. São Paulo: Duas Cidades; Rio de Janeiro: Ouro sobre azul, 2004.

COELHO, Nelly Novaes. A natureza da literatura infantil. In: COELHO, Nelly Novaes. Literatura infantil: teoria, análise, didática. São Paulo: Moderna, 2000.

DEBUS, Eliane; CINTRA, Simone; SPENGLER, Maria Laura P. A literatura infantil e juvenil produzida em Santa Catarina: escritores, ilustradores, tradutores e seus títulos. Florianópolis: NUP/UFSC, 2013.

FAVILLI, Elena, CAVALLO, Francesca. Histórias de ninar para garotas rebeldes. São Paulo: Vergaras \& Ribas Ed., 2017.

ISAACSON, Walter. Os inovadores: uma biografia da revolução digital. Tradução Luciano Vieira Machado e Pedro Maia Soares. São Paulo: Companhia das Letras, 2014.

JENKINS, Henry. Cultura da convergência. 2. ed. São Paulo: Aleph, 2009.

LÉVY, Pierre. Cibercultura. 3. ed. São Paulo: Editora 34, 1999.

MADDALENA, Tania Lucía; D’ÁVILA, Carina; SANTOS, Edméa. Visual Storytelling e PesquisaFormação na Cibercultura. p. 290-305. Revista Brasileira de Pesquisa (Auto)Biográfica. Salvador, v. 3, n. 7, jan./abr. 2018.

NUÑEZ, Emília. A menina da cabeça quadrada. Ilustração de Bruna Assis Brasil. São Paulo: Tibi, 2017.

PAULINO, Graça. Das leituras ao letramento literário: 1979-1999. Belo Horizonte: FaE/UFMG; Pelotas: EdUFPel, 2010.

PETIT, Michèle. $A$ arte de ler ou como resistir à adversidade. São Paulo: Editora 34, 2009.

SANTAELLA, Lúcia. Para compreender a ciberliteratura. p. 229-240. Texto Digital. Florianópolis, v. 8, n. 2, jul./dez. 2012.

SANTOS, Edméa. Pesquisa-Formação na Cibercultura. Santo Tirso: Whitebooks, 2014.

STREET, Brian. Letramentos sociais: abordagens críticas do letramento no desenvolvimento, na etnografia e na educação. Tradução Marcos Bagno. São Paulo: Parábola Editorial, 2014. 
XAVIER, Antônio Carlos. Leitura, texto e hipertexto. In: MARCUSCHI, Luís Antônio; XAVIER, A. C. Hipertexto e gêneros digitais. Rio de Janeiro: Lucerna, 2004.

Submetido em outubro de 2019. Aprovado em janeiro de 2020.

\section{Informações da autora}

Terezinha Fernandes

Docente da Universidade Federal de Mato Grosso (UFMT), Departamento de Ensino e Organização Escolar e Programa de Pós-graduação em Educação (PPGE).

E-mail: terezinha.ufmt@gmail.com

ORCID: http://orcid.org/0000-0002-1040-424X

Link Lattes: http://lattes.cnpq.br/4491000679954389 